\title{
The key role of the productive structure in the countercyclical productivity in Spain
}

\author{
Andrés Maroto-Sánchez ${ }^{1}$ • Juan R. Cuadrado-Roura ${ }^{2 *}$ \\ ${ }^{I}$ Department of Economic Analysis: Economic Theory, Autonomous University of Madrid, Spain \\ ${ }^{2}$ Department of Economics and Business, University of Alcala, Spain
}

Received: 24 June 2013

Revised: 23 September 2013

Accepted: 24 September 2013

\begin{abstract}
One of the most controversial topics of the Spanish economy is the countercyclical behavior of its productivity, both in the expansive years and during the recent financial and economic crisis. Additionally, this countercyclical pattern is unique among the economies of its area. This letter considers one of the likely answers to this fact: the Spanish productive structure, which is characterized by sectors such as construction and some service industries.
\end{abstract}

Keywords: productivity, business cycle, HP filter, productive structure

JEL Classification Codes: C50, E32, F44, L80, 040

\section{Introduction: motivation and the research question}

Productivity ${ }^{1}$ is one of the most analyzed topics in economic literature in recent years, mainly because there is ample evidence showing that long-term growth and productivity represent two sides of the same coin. Moreover, the fact that it is easier to hit the key in order to achieve a positive evolution of this variable, which depends on a variety of factors, is no less important. One reason, among many others, behind the complexity in the analysis of productivity is its susceptibility to the effects of economic cycles. In fact, there are various studies $^{2}$ confirming that in, many advanced economies, a positive or negative behavior of productivity could be due to such cyclical fluctuations, rather than to an efficiency increase in the use of other key elements such as capital accumulation or technological advances (Basu and Fernald, 2000).

\footnotetext{
*Corresponding author. E-mail: jr.cuadrado@uah.es.

Citation: Maroto-Sánchez, A. and Cuadrado-Roura, J.R. (2013) The key role of the productive structure in the countercyclical productivity in Spain, Economics and Business Letters, 2(3), 86-93.

${ }^{1}$ See Cuadrado and Maroto (2012a) or Maroto and Cuadrado (2006) for a more in-depth review of the analysis of productivity, especially of the Spanish case.

${ }^{2}$ See Maroto (2011) and Chap. 4 of Cuadrado and Maroto (2012a) for a more in-depth review of the relationship between productivity and economic cycles.
} 
The case of Spain is undoubtedly one of the most paradigmatic in this respect. During the period of economic 'success' 2000-2007 - featuring high rates of economic growth (average rate of $3,4 \%$ ) coupled with notable job creation (more than 2.7 million new jobs) - that preceded the crisis, the productivity variable was the only one which did not follow this positive pattern. In contrast, whilst recent years have been marked by a deep economic and financial crisis, with low or negative growth rates and rapid job destruction, aggregate data show a striking improvement in apparent labor productivity. This fact does not only contrast with economic observations in previous years, but also with the recent experience in most developed countries.

It's highlighted a different behavior of the Spanish economy in the European context (see Figure 1), before and after the current crisis. It is particularly striking how, until 2006, Spain presented the worst performance in terms of productivity, mainly due to the continuous process of job creation experienced since the mid-80s. However, this situation changed radically towards the end of 2007; most countries previously found in the upper quadrants moved to the lower ones, and vice versa. In particular, Spain is currently among the countries with highest productivity, regardless of the fact that this improvement is due to a profound process of job destruction, since the growth of its production has been below the European average and the accumulation of productive capital has remained at low levels.

The best explanation for the countercyclical behavior of Spanish productivity possibly lies in the deep process of job destruction suffered in recent years, in turn linked to the country's specialization pattern, characterized by activities which are markedly influenced by cyclical components, including construction and final consumption services, such as tourism, personal services, trade and other market services industries. Therefore, this work aims to answer the following question: does the Spanish productive structure explain the countercyclical pattern of its productivity?

With this objective in mind, the text is organized as follows: after this brief introduction presenting the motivation for the work (comparing the Spanish case with other neighboring countries displaying procyclical productivity patterns), both the data and the main methodological aspects are described. Subsequently, we analyze the role of the sectoral composition in the cyclical behavior of Spanish productivity, emphasizing aspects such as coherence, volatility and cyclical synchrony. The work concludes by offering a response to the hypothesis through some ideas which should be kept in mind. 
Figure 1. Impact of the crisis on production, employment and productivity in Europe: Comparison $1995-2006$ vs. $2007-2011$

PANEL A: 1995-2006

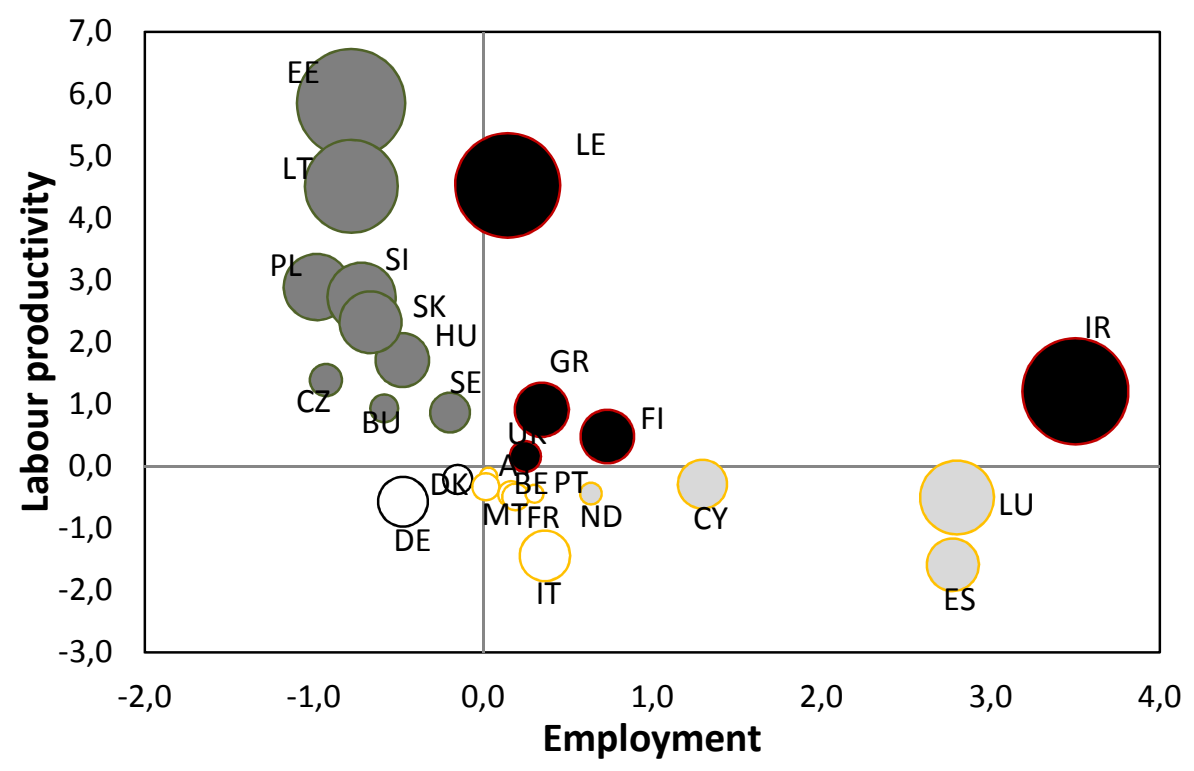

PANEL B: 2007-2010

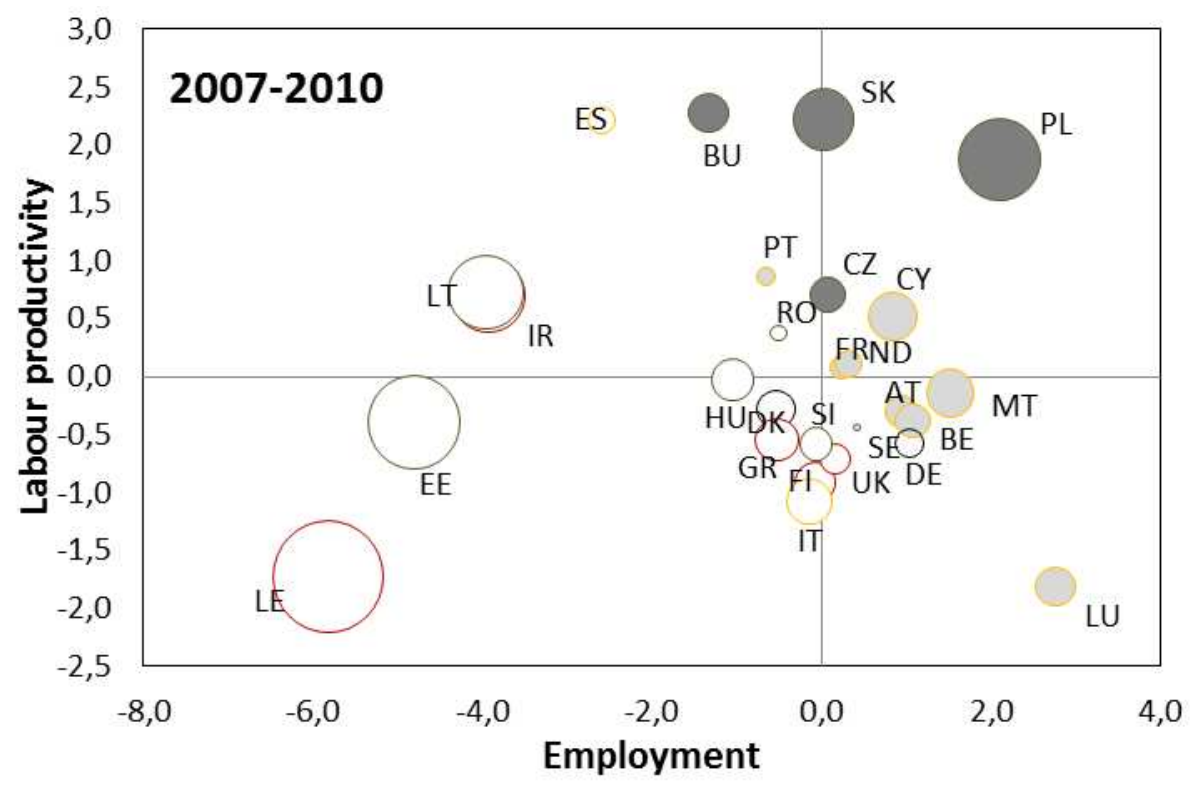

Note: This methodology distinguishes between dynamic (first quadrant), restructuring (second quadrant), declining (third quadrant) and labor-intensive (fourth quadrant) countries. The differential between the growth rate of each country and the European average is presented in the X-axis for employment and in the Y-axis for labor productivity. Colors are used to highlight the evolution of each country in both periods.

AT: Austria; BE: Belgium; BU: Bulgaria; CY: Cyprus; CZ: Czech Republic; DE: Germany; DK: Denmark; EE: Estonia; ES: Spain; FI: Finland; FR: France; GR: Greece; HU: Hungary; IR: Ireland; IT: Italy; LE: Latvia; LT: Lithuania; LU: Luxemburg; MT: Malta; ND: Netherlands; PO: Poland; PT: Portugal; RO: Romania; SI: Slovenia; SK: Slovakia; SE: Sweden; UK: United Kingdom.

Source: Own elaboration from the TCB (2012) 


\section{Data and methods}

The data used in this letter come from two sources: the database created by The Conference Board (Total Economy Database, 2012), which allowed us to work reliably with the international comparisons presented earlier; and the figures of the Contabilidad Nacional Trimestral (Quarterly National Accounts), prepared by the INE (2012), which have been used to develop the following productivity-cycle empirical analyses for the Spanish case.

When analyzing cyclical fluctuations, we need to estimate the underlying trend in the productivity series, in order to establish the structural or long-term component of the shortterm or cyclical deviations. Among the various methods found in the specialized literature ${ }^{3}$, we will use the filter ${ }^{4}$ introduced by Hodrick and Prescott in 1997 (hereinafter ' $H P$ '), whose formal expression is the following:

$$
\min \left\{\sum_{t=1}^{N}\left(Y_{t}-T_{t}\right)^{2}+\lambda \sum_{t=k+1}^{N}\left(\nabla^{k} T_{t}\right)^{2}\right\}
$$

where $Y_{t}$ represents the value of the original series, $T_{t}$ is the trend and $\nabla T_{t}=\mathrm{T}_{t}-\mathrm{T}_{t-1}$, $\nabla^{k}=\nabla\left(\nabla^{k-1}\right)$ is the lag operator for a specific smoothing parameter, $\lambda$. Following the seminal paper by Ravn and Uhlig (2002), we use a lambda equal to 1600 since frequency is quarterly for our analysis.

Nevertheless, the statistical properties of filtered or non-trend components still remain a matter of debate. For this reason, we will further analyze the sensitivity of our estimates through the calculation of volatility and cyclical synchrony measures. Therefore, the standard deviation of the filtered series is used as an approach of the volatility of the cyclical component in relative terms. Subsequently, we calculate correlation coefficients between productivity and economic growth in order to analyze whether aggregate and sectoral productivity behaves pro-cyclically or counter-cyclically, as well as the synchrony relating to the general cycle of such variables. Specifically, a positive (negative) and statistically significant value indicates that productivity is pro-cyclical (countercyclical), while values close to zero represent an absence of periodical correlation between both variables ${ }^{5}$. Additionally, if the correlation coefficient registers its maximum value (in absolute terms) during the period $t-i, t$ or $t+j$, we will state that the cycle is leading for $i$ periods, coincides or lags for $j$ periods compared to the general cycle, respectively.

\section{Main results}

Before attempting to answer the key question of this study - the relationship between the productive structure and the countercyclical pattern of Spanish productivity - we must point out some general features regarding the cyclical behavior of the Spanish economy ${ }^{6}$.

Firstly, it should be noted that, to date, Spain's economic recession periods had always exhibited a shorter duration than those of expansion. Similarly, the reduction in volatility of

\footnotetext{
${ }^{3}$ See Zarnowitz and Ozyldirim (2001) for a review of these different approaches. These authors came to the conclusion that very similar results were obtained with them.

${ }^{4}$ See Maroto (2011) for a detailed revision of the HP filter, other different methodological approaches, some of the advantages and problems of using it, the main reasons to choose it and other recent works which have opted for this filter in their analyses.

${ }^{5}$ For quarterly data, we use a cut-off point of 0.35 , approximating the values that reject the hypothesis that the correlation is null at a significance of $5 \%$ of a two-tailed t distribution.

${ }^{6}$ See Maroto and Cuadrado (2012b) for a more detailed analysis of the aggregate results of the cyclical behavior of Spanish productivity in recent years.
} 
the Spanish cycle, which had been observed from the 50s (Cuadrado and Ortiz, 2001) until the first half of the first decade of the $21^{\text {st }}$ century, suffered a change in 2006 and has subsequently increased during this period of crisis. Secondly, as illustrated by the data presented in the introduction, Spanish aggregate productivity displays a countercyclical behavior. Specifically, the correlation between productivity and economic cycles in Spain has not only been negative and statistically significant in the past two decades, but also such countercyclical behavior has been even more significant during the crisis period from late 2006 ( -0.89 vs -0.11 , with $P$-values of 0.000$)$. This fact is, perhaps, even more remarkable due to the fact that the relationship between the economic cycle and the behavior of employment in Spain is significantly procyclical (specifically 0.77 , with a $P$-value of 0.000 ).

The main conclusion extracted from the above data is that, in Spain, labor productivity has exhibited a significantly countercyclical behavior, contrary to that observed in neighboring countries. However, as expressed in the central hypothesis of this work, this pattern could presumably be influenced by the productive structure of the Spanish economy, as well as heterogeneity in the response of different productive sectors to the economic cycle, among other possible explanatory variables.

Figure 2. Comparison of the economic cycle by sectors in Spain. Sectoral productivity, 1995-2011 (3 quarter mobile average)

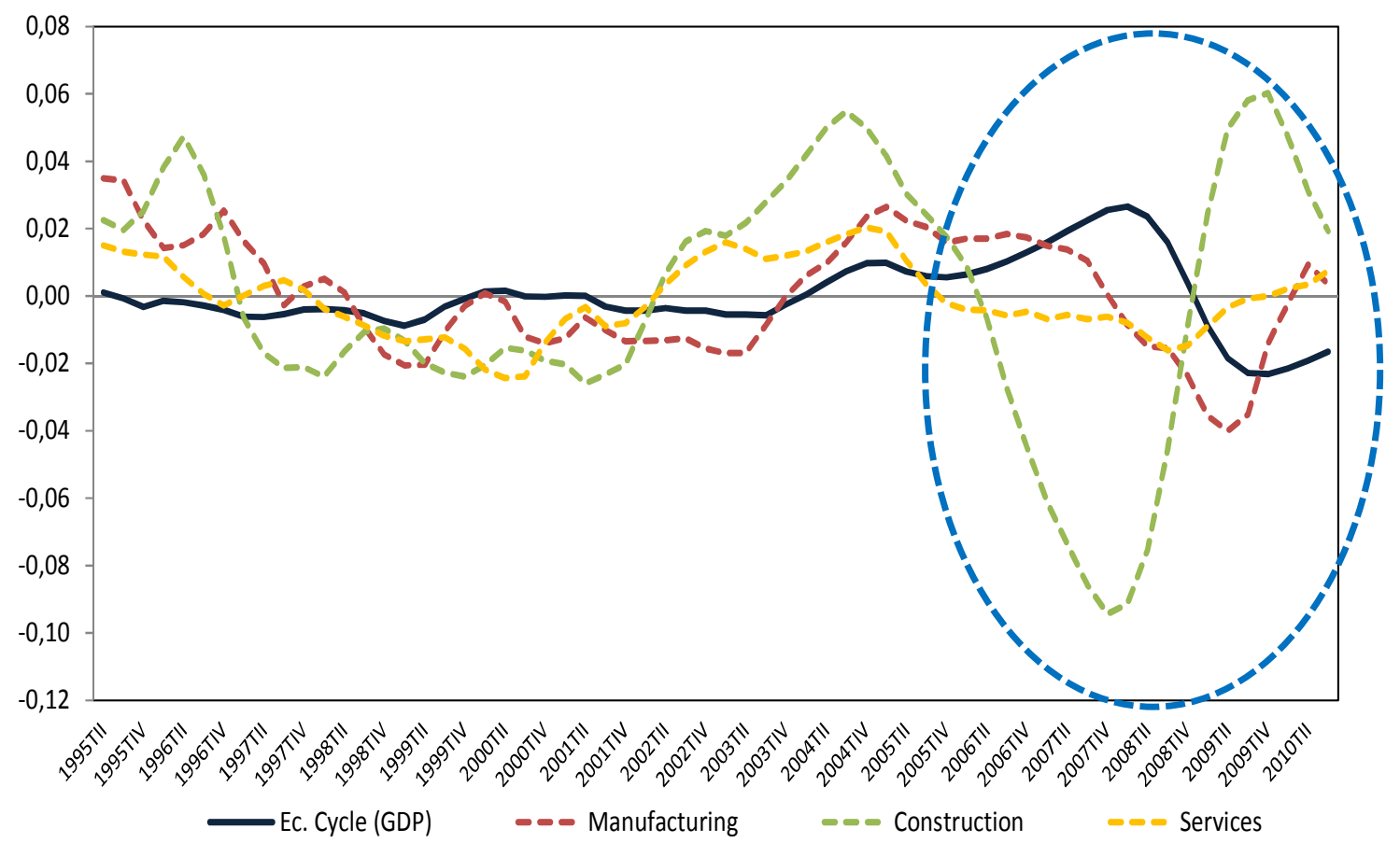

Source: Prepared by the authors on the basis of the Quarterly National Accounts (INE, 2012)

Results of the cyclical behavior at the sectoral level are shown in the Figure 2. The data show that not all sectors ${ }^{7}$ behave uniformly. Specifically, there are some sectors whose productivity exhibits a procyclical behavior, as in the cases of manufacturing and energy. The correlation coefficient between the cycle of their productivity and that of aggregate GDP is positive and statistically significant for the entire period analyzed $(0.30$ and 0.20 , respectively). However, this behavior becomes slightly weakened during the period of

\footnotetext{
${ }^{7}$ Although Figure 2 only shows data relating to manufacturing, construction and services, due to their relevance, the cyclical behaviors of the remaining, essential economic sectors have also been calculated. These results can be obtained from the authors by request.
} 
economic crisis, since the relationship between the productivity of manufacturing industries and the Spanish economic cycle has only been 0.20 . Prior to this point, there would be no examples of the countercyclical behavior being sought in Spanish productivity.

Moreover, additional sectors, such as construction and market services, are also studied, since they display the opposite behavior and their weight has been relevant to the Spanish productive system during the period of economic buoyancy. The series in Figure 2 show that, for both construction and services, the correlation coefficient between their productivity cycle and the economic cycle is not only negative $(-0.61$ and -0.31 , respectively), but also that this countercyclical behavior is markedly enhanced from the end of 2006, reaching statistically significant coefficients of -0.98 and -0.62 . Therefore, the behavior of these two productive sectors explains much of the countercyclical pattern of Spanish aggregate productivity.

Furthermore, the most recent works on cycles commonly explore their behavior through statistics that can provide a better understanding of these patterns than the graphic analyses and the correlations previously presented. For this reason, we can estimate volatility (measured as the standard deviation of cyclical fluctuations of the analyzed variable) and relative volatility (measured as the quotient between the volatility of the reference variable generally GDP - and the volatility of the rest of the analyzed variables). Both provide a clearer image of the magnitude of cyclical fluctuations, as well as of their relationship with the overall cycle. As far as the sectoral analysis that we are performing in this subsection is concerned, these indicators seem to be essential.

Table 1. Cyclical volatility of sectoral productivity in Spain

\begin{tabular}{|c|c|c|c|c|c|c|}
\hline & Total & Agriculture & Energy & Manufacturing & Construction & Services \\
\hline \multicolumn{7}{|c|}{ 1995-2011 } \\
\hline Volatility & 1.04 & 4.55 & 3.07 & 2.06 & 3.94 & 0.93 \\
\hline Rel Volatility & 1.00 & 4.39 & 2.96 & 1.99 & 3.80 & 0.89 \\
\hline \multicolumn{7}{|c|}{ 1995-2006 } \\
\hline Volatility & 1.09 & 4.98 & 2.62 & 1.85 & 2.83 & 1.04 \\
\hline Rel Volatility & 1.00 & 4.57 & 2.41 & 1.70 & 2.59 & 0.95 \\
\hline \multicolumn{7}{|c|}{$2007-2011$} \\
\hline Volatility & 0.73 & 2.86 & 4.19 & 2.50 & 5.99 & 0.43 \\
\hline Rel Volatility & 1.00 & 3.91 & 5.72 & 3.42 & 8.19 & 0.59 \\
\hline
\end{tabular}

Source: Prepared by the authors on the basis of the Quarterly National Accounts (INE, 2012)

The estimates regarding the volatilities of sectoral productivity in Spain during the period of 1995-2011 is exhibited in the Table 1. The expansive period (1995-2006) has a higher dispersion, not only in the overall economy but also in the agricultural and services sectors. Alternatively, the sub-period dominated by the crisis shows a lower overall volatility, although higher relative volatilities are observed in manufacturing, construction and energy.

To complement the analysis performed, we have carried out a study of cyclical synchrony between sectoral productivity and the economic cycle, aiming to contrast the hypothesis of the possible countercyclical behavior of Spanish productivity. To this end, we have estimated correlation coefficients between different time periods, leading, coincident or lagging, of the variable under study and the reference variable (which in this case will be the overall economic cycle or the cyclical fluctuation of national GDP). This reflects the level of coherence and synchrony between the cycles. Therefore, we will consider that productivity is pro-cyclical if its fluctuations follow the same direction as the economic cycle and thus show a positive correlation. If the fluctuations between both variables are opposed (i.e. when the cycle is expansive, the cycle of the variable contracts and vice versa) productivity will be countercyclical. Finally, if there is no relationship between them, productivity will be a- 
cyclical. On the other hand, it is also worth noting that aggregate and sectoral productivity may lead, coincide or lag in its cycle compared to the overall economic cycle. It will lead when rises (falls) occur sooner than in economic production. In contrast, if these falls occur as a result of fluctuations in economic activity, we will say that productivity is lagging. Finally, if the variations occur at the same time, the variables will be coincident.

Table 2. Coherence and cyclical synchrony of sectoral productivity in Spain

\begin{tabular}{lcccccc}
\hline & Total & Agriculture & Energy & Manufacturing & Construction & Services \\
\hline Coherence & Countercyclical & Acyclical (-) & Acyclical (-) & Pro-cyclical & Countercyclical & Countercyclical \\
Synchrony & Leading (2) & Lagging (5) & Lagging (4) & Lagging (3) & Coincident & Leading (4) \\
\hline \multicolumn{7}{c}{$\mathbf{1 9 9 5 - 2 0 0 6}$} \\
\hline Coherence & Acyclical (+) & Acyclical (-) & Acyclical (+) & Pro-cyclical & Acyclical (+) & Acyclical (+) \\
Synchrony & Coincident & Lagging (5) & Leading (5) & Leading (1) & Lagging (5) & Coincident \\
\hline & & & $\mathbf{2 0 0 7 - 2 0 1 1}$ & & \\
\hline Coherence & Countercyclical & Pro-cyclical & Acyclical (+) & Pro-cyclical & Countercyclical & Countercyclical \\
Synchrony & Leading (1) & Leading (5) & Leading (1) & Lagging (4) & Coincident & Leading (3) \\
\hline
\end{tabular}

Note: In brackets, the sign of the correlation in the case of coherence and the number of delays in the case of synchrony.

Source: Prepared by the authors on the basis of the Quarterly National Accounts (INE, 2012)

The main results obtained are listed in the Table 2, not only regarding the coherence, but also the cyclical synchrony of the sectoral productivity in Spain, always referring to the period as a whole herein analyzed.

The data show that Spanish productivity has presented a differentiated behavior before and after the beginning of the crisis, as has been highlighted throughout this letter. While the pattern was a-cyclical between 1995 and 2006, albeit with a positive and coincident relationship, in recent years it has become countercyclical (and statistically significant) and slightly leading (one period). Due to this fact, Spanish labor productivity has displayed the growth explained in the previous section, while the overall economic activity has registered a significant recession, similarly to the rest of the surrounding European economies, although for a more extensive time period than many of them.

At a sectoral level, we can again observe well-differentiated cyclical behaviors. On one side, the construction and services sectors largely explain the previously mentioned pattern for the overall economy, as the sign of their relationship with the sign of the economy has shifted from being positive to negative during the crisis. Additionally, these activities not only show the changing trend after the crisis but also the general countercyclical behavior of the overall productivity.

\section{Concluding discussion}

The aim of this study was clear: to answer the question of whether the production structure of the Spanish economy, characterized by a dominant weight of activities such as construction or services - especially in recent years -, could explain the countercyclical behavior of aggregate productivity in Spain, or not. After considering the results presented herein, the conclusion becomes evident: yes, it does. Clearly, this response is subject to certain qualifications, since this work does not analyze other possible causes or the interaction with other possible explanatory factors.

However, using proven techniques, the data show, on the one hand, a countercyclical behavior of productivity in Spain, which is contrary to that observed in other European countries during recent decades. More importantly, from the standpoint of the initial 
hypothesis, the work also shows that this pattern is influenced by the internal behavior of sectors such as construction and services, particularly those intended for final consumption markets. On the other hand, our analysis has also contributed adequate responses to questions such as volatility of the cycle which, although quite clearly present until 2005-2006, has undergone a very significant change from the latter years in the sense that the volatility of the Spanish cycle during the crisis has increased. Additionally, the study of coherence and cyclical synchrony has led us to conclude that the countercyclical behavior of Spanish productivity has become even more pronounced during the economic and financial crisis which Spain has suffered since the end of 2007.

\section{References}

Cuadrado-Roura, J.R. and Ortiz, A. (2001) Business cycle and service industries: general trends and the Spanish case, The Service Industries Journal, 21(1), 103-122.

Cuadrado-Roura, J.R. and Maroto-Sánchez, A. (2010). Servicios y regiones en España, Colección Estudios, 28, Funcas, Madrid.

Cuadrado-Roura, J.R. and Maroto-Sánchez, A. (2012a) El problema de la productividad en España: Aspectos estructurales, cíclicos y sectoriales, Ed. Funcas, Madrid.

Cuadrado-Roura, J.R. and Maroto-Sánchez, A. (2012b) Efectos de los movimientos cíclicos en la productividad española. Un análisis agregado y por sectores, Cuadernos Económicos de ICE, 84, 33-55.

Hodrick, R. and Prescott, E.C. (1997) Post-war US business cycles: an empirical investigation, Journal of Money, Credit and Banking, 29(1), 1-16.

INE (2012) Contabilidad Nacional Trimestral, Instituto Nacional de Estadística, Madrid.

Maroto, A. (2011) Productivity growth and cyclical dynamics in the service sector. The Spanish case, Service Industries Journal, 31(5), 725-745.

Maroto, A. and Cuadrado-Roura, J.R. (2006) La productividad en la economía española, Colección Estudios, Instituto de Estudios Económicos, Madrid.

Ravn, M. and Uhlig, H. (2002) On adjusting the HP filter for the frequency of observations, Review of Economics and Statistics, 84(2), 371-380.

TCB (2012) Total Economy Database, The Conference Board, Washington DC.

Zarnowitz, V. and Ozyildirim, A. (2001) Time series decomposition and measurement of business cycles, trends and growth cycles, Conference Board Working Paper 01-04, The Conference Board, Washington DC. 